\title{
Risk factors associated with overweight and obesity among reproductive aged females residing in Bharatpur Metropolitan City
}

\begin{abstract}
Overweight and obesity is becoming one of the major public health problems in developing countries like Nepal. A cross sectional study was conducted to assess the risk factors associated with overweight and obesity among reproductive aged females of 15-49 years residing in Bharatpur metropolitan city. Anthropometric measurement was used to determine Body Mass Index (BMI), Waist Circumference (WC) and Waist Hip Ratio (WHR). Data on socio-demographic, physical activity, dietary and behavioral factors was collected using structured questionnaire. Microsoft excel and SPSS version 20 were used to analyze data and chi square test was performed to analyze the factors associated with BMI, WC and WHR cut-offs.
\end{abstract}

The result of this study revealed that $32.3 \%$ of females were overweight and $9.7 \%$ of females were obese. Similarly, on the basis of waist circumference $69 \%$ of females were abdominally obese and on the basis of waist hip ratio $68 \%$ of females were abdominally obese. Mean BMI was found to be $24.1 \mathrm{c} 10.01 \mathrm{~kg} / \mathrm{m}^{2}$, waist circumference was found to be $86.41 \pm 13.091 \mathrm{~cm}$ and waist hip ratio was found to be $0.89 \pm 0.108$. This study shows that age, marital status, parity, stress, sleeping time, calorie intake, carbohydrate intake, physical activity and fruits consumption were found to be significantly associated $(\mathrm{P}<0.05)$ with overweight and obesity. Age, marital status, parity, calorie intake, fat intake, physical activity and fruits consumption were found to have significant association $(\mathrm{P}<0.05)$ with waist circumference. Similarly, age, marital status, parity, cloth wear, calorie intake, carbohydrate intake and physical activity were found to be significant predictors $(\mathrm{P}<0.05)$ of WHR in the study. The findings show a clear evidence of the rising trends of overweight and obesity among reproductive aged female. Overall this study indicate that efforts should be made to address the problem of overweight and obesity, by addressing the factors associated and minimize its consequences.
Volume 10 Issue $3-2020$

\author{
Sadikshya Subedi, Richa Bhattarai, Rojina \\ Bista \\ Department of Nutrition and Dietetics, Central Campus of \\ Technology, Nepal
}

Correspondence: Sadikshya Subedi, Department of Nutrition and Dietetics, Central Campus of Technology, Dharan, Nepal, Tel +6/46607/488, Email sadikshyasubedi7@gmail.com

Received: June 15, 2020 | Published: June 25, 2020

Keywords: overweight, obesity, BMI, WC, WHR

Abbreviations: $\mathrm{BF}$, body fat; $\mathrm{BMI}$, body mass index; $\mathrm{CHD}$, coronary heart disease; CNS, central nervous system; WC, waist circumference; WHR, waist hip ratio

\section{Introduction}

Overweight and obesity are abnormal condition that results from excessive fat accumulation that may impair health. ${ }^{1}$ Body mass index (BMI) is a simple index of weight-for-height that is commonly used to classify overweight and obesity in adults. A person with a BMI equal to or more than $25 \mathrm{~kg} / \mathrm{m}^{2}$ is considered overweight and a person with a BMI of $30 \mathrm{~kg} / \mathrm{m}^{2}$ or more is generally considered obese. ${ }^{1}$ Waist to hip ratio (WHR) and waist circumference (WC) are the indicators of central obesity. ${ }^{2,3}$ WHR above 0.85 is considered as central obesity whereas $\mathrm{WC}$ alone above $80 \mathrm{~cm}$ is considered as being centrally or abdominally obese. ${ }^{4}$ The fundamental cause of obesity and overweight is an energy imbalance between calories consumed and calories expended. An increased intake of energy dense food and increasingly sedentary nature of life style and work, and increasing urbanization have led to global epidemic of overweight and obesity. ${ }^{1}$ Age, parity, marital status, socio-economic status, physical activity, fruit consumption and many others factors have been reported as causative factors of overweight and obesity in reproductive aged females. ${ }^{5,6}$ There are an overwhelming evidence on the association of obesity to number of medical conditions. These include: insulin resistance, glucose intolerance, diabetes mellitus, hypertension, dyslipidemia, sleep apnea, arthritis, hyperuricemia, gall bladder diseases, and certain types of cancer. The independent association of obesity seems also clearly established for coronary artery diseases, heart failures, cardiac arrhythmias, stroke, and menstrual irregularities. ${ }^{\text {? }}$

In 2016, globally more than 1.9 billion adults, were overweight and 650 million were obese, whereas $39 \%$ of adults

were overweight and $13 \%$ were obese globally. Among these obese adult world's population $11 \%$ are men and $15 \%$ are women. ${ }^{1}$ Considering the age specific fertility rates, women of age group 15-49 years are called reproductive aged women. ${ }^{8}$ Obesity among women of reproductive age varies across low and middle-income countries from 3.4 to $73.7 \%$. These countries are currently undergoing an epidemiological transition, with a shift in disease patterns from communicable to non-communicable conditions. Globalization and urbanization are recognized as main drivers of this transition, mediated by changes in lifestyles and habits. ${ }^{9}$

Nepal falls in medium human development category ranking 144 among 188 countries in the world. Nepal has upgraded from low human development category with lifting of standard of living, increase in knowledge and long and healthy life. ${ }^{10}$ The total population 
of Nepal is 26.6 million and $17 \%$ population resides in urban area. ${ }^{11}$ The annual rate of urbanization was found at $3.2 \%$ in $2014^{12}$ which also influences prevalence of obesity.

Nepal is experiencing nutrition transition in recent decades which has resulted in consumption of high fat and sugar foods and decreased physical activity. The mean time spent by female on physical activity has decreased from 291.7 minutes to 263.9 minute per day. ${ }^{13,14}$ Similarly, rapidly growing or developing economies of the country has resulted in the globalization of food markets, fast food chains and the increasing availability of street vendors who offer products at very competitive value due to economical acquisition of inputs such as raw and processed foods which increases the consumption of energy dense food primarily leading to overweight and obesity. ${ }^{15}$ There is a dramatic decrease in the consumption of fruits and vegetables in Nepal which decreased from 4 number of servings per day in 2007 to 1.8 in $2013 .{ }^{16,17}$

In Nepal trends of overweight and obesity is found to be increasing in both male and female with $7.1 \%$ overweight and $2.4 \%$ obesity to $22.1 \%$ overweight and $4.8 \%$ obesity between 2007 to 2013 . Similarly mean waist to hip ratio was found to be 0.55 in 2007 study while 2013 STEPS survey shows this figure to 0.9. The current prevalence of overweight and obesity is more among females as compared to males in Nepal. ${ }^{13-21}$ The combined prevalence of overweight and obesity in female has increased from $1.6 \%$ to $22.2 \%$ in 2016 and in men overweight and obesity is found to be $17 \% .^{14,22}$

Bharatpur Metropolitan city is located at the center of Mahendra Highway and Kathmandu - Birganj (North-South) road, in the Chitwan district, Narayani zone of central development region. It is the district headquarter of the Chitwan district, as well as a separate metropolitan authority, a fifth largest city and one of the fast growing cities of Nepal. It lies on the left bank of Narayani River and serves as a commercial center of Chitwan district and central region of Nepal. It has been declared metropolitan city on 2017 with including Chitrawan municipality, Narayani municipality and Kabilas VDC. ${ }^{14}$

Objectives: To identify the risk factors associated with overweight and obesity among reproductive aged (15-49 years)females residing in Bharatpur Metropolitan city, to assess physical activity level, behavioral factors and dietary factors with the help of questionnaire, to identify risk factors directly and indirectly associated with overweight and obesity.

\section{Material and methods}

This study employed a cross-sectional design to explain overweight and obesity and factors associated with overweight and obesity in the reproductive aged females residing in Bharatpur. Permission to conduct study was received from Nutrition and Dietetics Department,
Central Campus of Technology. Ethical approval was obtained from National Health and Research Council (NHRC). The objectives of the research were explained in simple language and an informed written and verbal consent was obtained from all the participants. Privacy and confidentiality of collected data was ensured. Research instruments used in the survey were as follows.

a. Weighing Machine: Weighing machine manufactured by Microlife Pvt. Ltd, with the capacity of $180 \mathrm{~kg}$ and having the least count of $0.1 \mathrm{Kg}$ (1piece) was used.

b. Stadiometer: Stadiometer was used to measure height with the capacity of $197 \mathrm{~cm}$ and having the least count of $0.1 \mathrm{~cm}$.

c. Measuring tape: A non-stretchable flexible measuring tape was used to measure waist and hip circumference.

d. Questionnaire: A well designed, structured and pretested set of questionnaire was used to collect information on sociodemographic and economic data, physical activity, dietary intake and behavioral characteristics.

e. Measuring utensils: Standardized utensils were used for taking 24 hour dietary recall.

\section{Study variables}

\section{Dependent variables}

The dependent variables under this study were defined as:

a. Waist circumference $(\mathrm{cm})$ : Women with waist circumference above $80 \mathrm{~cm}$ were identified as being abdominally obese. ${ }^{13}$

b. Waist to Hip ratio.

WHR is calculated using formula, WHR=Waist circumference $(\mathrm{cm}) /$ Hip circumference $(\mathrm{cm})$

Women with waist to hip ratio greater than 0.85 were considered as abdominally obese (WHO, 2011).

\section{Independent variables}

Independent variables included in this study were as follows:

a. Socio-economic and demographic variables: Age, caste, religion, marital status, income, occupation, education, parity, family size.

b. Physical activity:Physical activity was categorized as low, moderate and high according to the score of each individual calculated following the short IPAQ questionnaire. For this total MET-minutes/week was calculated and physical activity level was determined as shown below:

Total MET - minutes $/$ week $=$ Walk $($ METs $\times \min \times$ days $)+$ Moderate $($ METs $\times \min \times$ days $)+$ vigorous $($ METs $\times$ min $\times$ days $)$.

Where, MET factors for walk, moderate activity and vigorous activity are 3.3,4 and 8 respectively. IPAQ categorical score is as follows:

I. Low: No physical activity is performed or physical activity with MET values less than 600 MET per week activity. ${ }^{23}$

II. Moderate: Physical activity with MET value 600 or greater than 600 per week or 3 or more day of vigorous activity of at least 20 minutes per day activity. ${ }^{24}$
III. Vigorous: Vigorous-intensity activity on at least 3 days and accumulating at least 1500 or 7 or more days more days of any combination of walking, moderate or vigorous intensity activities accumulating at least 3000 MET-minutes/week activity. ${ }^{25}$

Adequacy of physical activity for each individual was also determined according to WHO recommendation. WHO has recommended that adults aged 18-64 should do at least 150 minutes of moderate-intensity aerobic physical activity throughout the week or 
do at least 75 minutes of vigorous-intensity aerobic physical activity throughout the week or an equivalent combination of moderate- and vigorous-intensity activity. ${ }^{26}$

\section{Dietary intake}

With the help of information obtained from dietary assessment (24 hour dietary recall) nutrients like carbohydrates, fat, protein, calcium as well as total calorie were calculated and classified according to WHO recommendations. It is recommended that $15-30 \%$ of total calories should be included from fat. ${ }^{11}$ Similarly, it is recommended that $55-75 \%$ of total calories should be included from carbohydrate. ${ }^{27}$ Protein intake should $0.83 \mathrm{gm} / \mathrm{kg} .{ }^{28}$ Recommendation for total calories is based on the energy requirement of an individual. Total energy requirement is calculated as follows: Recommended energy for:

Less than 18 years $=(13.384 \times$ weight +692.6$) \times \mathrm{PA}$ factor

18 to 30 years $=(14.818 \times$ weight +486.6$) \times \mathrm{PA}$ factor

31 to 60 years $=(8.126 \times$ weight +845$) \times$ PA factor

Physical activity factor to calculate energy

\begin{tabular}{ll}
\hline Physical activity level & Factors \\
\hline Low & 1.53 \\
Moderate & 1.76 \\
Heavy & 2.25 \\
\hline
\end{tabular}

Beside these it is recommended to consume $600 \mathrm{mg}$ of calcium per day. Fruits and vegetables are recommended to consume minimally 400 to 500 gram/day excluding tubers like potato, cassava etc. ${ }^{29}$

a. Health related characteristics: Menstrual disorders, use of contraceptives.

b. Behavioral characteristics: Watching TV while eating, sleep, stress, outside eating, smoking, alcohol intake, cloth wear.

\section{Inclusion criteria}

Women residing in Bharatpur metropolitan city of age between 15-49 years of age were included in the study

\section{Exclusion criteria}

I. Females who were below 15 years and above age 49 .

II. Females who were seriously ill, pregnant and lactating women.

III. Females who were residing temporarily in Bharatpur

\section{Sample size}

The sample size was determined by using a single proportional formula assuming the combined prevalence rate of overweight and obesity to be $24 \%$ in the survey area, $95 \%$ confidence interval (CI), $5 \%$ margin of error (d) and 7\% non-response rate is added to the total calculated sample size. The WHO STEPS NCD survey conducted in Nepal in 2013 was taken as the reference proportion.

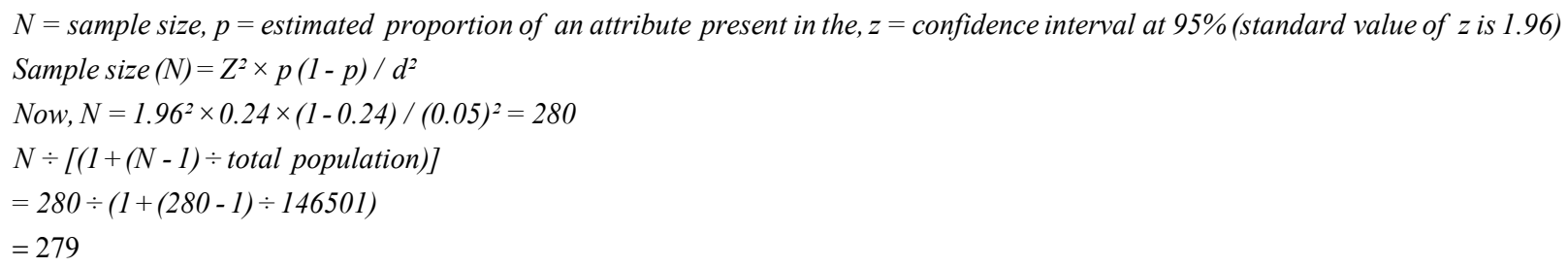

Considering non-response rate as $7 \%$, the adjusted sample size is calculated to be 300 .

\section{Sampling technique}

All wards were chosen for sample selection. Number of households from each ward was calculated on the basis of probability proportionate sampling technique. Alternate households were chosen for sample selection according to systematic sampling. Only one female from each household were chosen for study

\section{Data analysis}

Collected data was manually edited and coded and entered into a database at end of each day. Microsoft excel 2010 and SPSS version 20 was used to analyze data. Descriptive analysis was used to describe percentage and distribution of respondents by socio demographic variables, physical activity, dietary patterns, medical characteristics and behavioral characteristics. Chi-square test was used to find out the association between overweight and obesity and its associated factors.

\section{Results}

The result concluded that that $42 \%$ of women were overweight or obese. Likewise, $68 \%$ of women were abdominally obese using WHO i.e. WHR $>0.84$ criteria while $69 \%$ were abdominally obese using IDF criteria i.e. WC $>80 \mathrm{~cm}$. Mean BMI was found to be $24.1 \pm 10.01 \mathrm{~kg} /$ $\mathrm{m}^{2}$, waist circumference was found to be $86.41 \pm 13.091 \mathrm{~cm}$, waist hip ratio was found to be $0.89 \pm 0.108$.

Out of total 300 females assessed, maximum number of participants i.e. $33 \%$ were from $40-49$ years (Table 1). Nearly three fourth of females $(71.0 \%)$ were married and half of the females $(50.3 \%)$ had $1-2$ children. This study showed that $21.3 \%$ of females had low physical activity (Table 2). Distribution of nutrient intake showed that more than three fourth $(78 \%)$ of females had inadequate calorie intake, more than half (64.3\%) of females had adequate protein intake, $36 \%$ of females had high fat intake, majority of females $(85 \%)$ had low carbohydrate intake and more than half of females $(65.3 \%)$ had inadequate calcium intake (Table 3).

This study found that age $(\mathrm{P}=0.000)$, marital status $(\mathrm{P}=0.000)$, parity $(\mathrm{P}=0.000)$, sleeping time $(\mathrm{P}=0.031)$, stress $(\mathrm{P}=0.018)$, calorie intake $(\mathrm{p}=0.000)$, carbohydrate intake $(\mathrm{P}=0.000)$, physical activity $(\mathrm{P}=0.000)$ and fruits consumption $(\mathrm{P}=0.032)$ are found to be significantly associated with overweight and obesity (Tables $3 \& 4$ ). Other factors like type of family, family size, contraceptives, eating while watching $\mathrm{TV}$, breakfast skipping, protein intake, dairy products intake, drinking alcohol, GLV intake were not associated $(\mathrm{p}<0.05)$ with overweight and obesity. 
Table I Distribution of surveyed population by age group $(n=300)$

\begin{tabular}{lll}
\hline Variable & Frequency & Percent \\
\hline Age & & \\
$15-19$ & 34 & 11.3 \\
$20-29$ & 74 & 24.7 \\
$30-39$ & 93 & 31 \\
$40-49$ & 99 & 33
\end{tabular}

Table 2 Distribution of physical activity $(n=300)$

\begin{tabular}{lcl}
\hline Variable & Frequency & Percent \\
\hline \multicolumn{2}{l}{ Physical activity } \\
\hline Low & 64 & 21.3 \\
Moderate & 159 & 53 \\
Heavy & 77 & 25.7 \\
\hline
\end{tabular}

Table 3 Distribution of nutrients intake $(n=300)$

\begin{tabular}{lll}
\hline Variables & Frequency & Percent \\
\hline Calorie & & \\
\hline Adequate & 61 & 20.3 \\
Inadequate & 239 & 79.7 \\
Protein & & \\
Adequate & 189 & 63 \\
Inadequate & 111 & 37 \\
Fat & & \\
Low & 33 & 11 \\
Normal & 152 & 50.7 \\
High & 115 & 38.3 \\
Carbohydrate & & \\
Low & 238 & 79.3 \\
Normal & 50 & 16.7 \\
High & 12 & 4 \\
Calcium & & 65.3 \\
Adequate & 196 & \\
Inadequate & 104 & \\
\hline & & \\
\hline
\end{tabular}

Table 4 Factors associated with WC of reproductive aged female $(n=300)$

\begin{tabular}{|c|c|c|c|c|c|}
\hline Factors & Category & $\begin{array}{l}\text { Overweight and } \\
\text { obesity }\end{array}$ & $\begin{array}{l}\text { Non overweight and } \\
\text { obese }\end{array}$ & Chi- Square & P-value \\
\hline & & Frequency (\%) & Frequency (\%) & & \\
\hline \multirow[t]{4}{*}{ Age } & $15-19$ & $5(14.7)$ & $29(85.3)$ & 37.433 & $0.000 *$ \\
\hline & $20-29$ & $42(56.8)$ & $32(43.2)$ & & \\
\hline & $30-39$ & $72(77.4)$ & $21(22.6)$ & & \\
\hline & $40-49$ & $88(88.9)$ & II(II.I) & & \\
\hline Marital & Married & I $73(79.0)$ & $46(21.0)$ & 37.885 & $0.000 *$ \\
\hline Status & Unmarried & $34(42.0)$ & $47(58.0)$ & & \\
\hline \multirow[t]{3}{*}{ Parity } & 0 & $34(39.5)$ & $52(60.5)$ & & \\
\hline & $\mathrm{I}-2$ & $116(76.82)$ & $35(23.2)$ & 52.809 & $0.000 *$ \\
\hline & $\geq 3$ & $57(90.4)$ & $6(9.5)$ & & \\
\hline Physical & Low & $57(89)$ & $7(10.9)$ & 22.513 & $0.000 *$ \\
\hline \multirow[t]{2}{*}{ activity } & Moderate & $110(69.1)$ & $49(30.8)$ & & \\
\hline & Heavy & $40(51.94)$ & $37(48.1)$ & & \\
\hline
\end{tabular}


Similarly, age $(\mathrm{P}=0.000)$, marital status $(\mathrm{P}=0.000)$, parity $(\mathrm{P}=0.000)$, calorie intake $(\mathrm{P}=0.002)$, fat $(\mathrm{P}=0.000)$, physical activity $(\mathrm{P}=0.000)$ and fruits consumption $(\mathrm{P}=0.000)$ were found to have significant association with waist circumference measurement (Table 4). Other factors like type of family, family size, eating while watching $\mathrm{TV}$, breakfast skipping, protein intake, drinking alcohol were not associated with overweight and obesity. Other factors like type of family, family size, use of contraceptives, eating while watching TV, protein intake, carbohydrate intake, dairy products intake, drinking alcohol, GLV intake were not associated $(\mathrm{p}<0.05)$ with overweight and obesity. The chi-square analysis showed that age $(\mathrm{P}=0.000)$, marital status $(\mathrm{P}=0.000)$, parity $(\mathrm{P}=0.000)$, stress $(\mathrm{P}=0.018)$, sleeping time $(\mathrm{P}=0.031)$, calorie intake $(\mathrm{P}=0.000)$ (Table 5), physical activity $(\mathrm{P}=0.000)$, carbohydrate intake $(\mathrm{P}=0.000)$ and fruits consumption $(\mathrm{P}=0.032)$ were significantly associated with $\mathrm{BMI}$ as shown in Table 5 .

Table 5 Dietary Factors associated with WC of reproductive aged female $(n=300)$

\begin{tabular}{llllll}
\hline Factors & Category & $\begin{array}{l}\text { Overweight } \\
\text { and obesity }\end{array}$ & $\begin{array}{l}\text { Non overweight } \\
\text { and obesity }\end{array}$ & $\begin{array}{l}\text { Chi } \\
\text { Square }\end{array}$ & P-value \\
\hline Calorie & Adequate & $55(90.2)$ & $6(9.8)$ & 16.034 & $0.000^{*}$ \\
& Inadequate & $152(63.6)$ & $87(36.4)$ & & \\
Fat & Low & $20(60.6)$ & $13(39.4)$ & & 0.01 I $^{*}$ \\
& Adequate & $96(63.2)$ & $56(36.8)$ & 9.03 & \\
& High & $91(79.1)$ & $24(20.9)$ & & $0.000^{*}$ \\
\multirow{2}{*}{ Fruits } & Regular & $61(59.8)$ & $41(40.2)$ & 22.742 & \\
& Frequent & $12(41.3)$ & $17(58.6)$ & & \\
& Rare & $134(79.2)$ & $35(20.7)$ & & \\
\hline
\end{tabular}

Considering WHR, factors associated are age $(\mathrm{P}=0.000)$, marital status $(\mathrm{P}=0.000)$, parity $(\mathrm{P}=0.000)$, cloth wear $(\mathrm{P}=0.035)$, dietary factors (Table 6) i.e. calorie intake $(\mathrm{P}=0.000)$ and carbohydrate intake $(\mathrm{P}=0.009)$, carbohydrate $(\mathrm{P}=0.009)$ and physical activity $(\mathrm{P}=0.001)$ as shown in Table 7 . There are many factors like age, marital status, parity, sleeping time, stress, cloth wear, calorie intake, fat intake, carbohydrate intake, physical activity and fruit consumption which are directly associated with overweight and obesity in reproductive aged females (Table 8). Among all these factors age, marital status, parity, calorie intake and physical activity were found to be commonly associated factors in all indicators of overweight and obesity i.e. BMI, WC and WHR which is shown in Tables $9 \& 10$.

Table 6 Factors associated with BMI of reproductive aged female $(n=300)$

\begin{tabular}{|c|c|c|c|c|c|}
\hline Factors & Category & $\begin{array}{l}\text { Overweight and Obesity } \\
\text { Frequency (\%) }\end{array}$ & $\begin{array}{l}\text { Non overweight and } \\
\text { obese Frequency (\%) }\end{array}$ & $\begin{array}{l}\text { Chi- } \\
\text { square }\end{array}$ & P-value \\
\hline Age & $15-19$ & $3(8.8)$ & $3 \mid(9 \mid .2)$ & 44.83 & $0.000 *$ \\
\hline $20-29$ & $16(21.6)$ & $58(78.4)$ & & & \\
\hline $30-39$ & $47(50.5)$ & $46(49.5)$ & & & \\
\hline $40-49$ & $60(60.60)$ & $39(39.4)$ & & & \\
\hline Marital & Married & III(50.7) & $108(49.3)$ & 22.681 & $0.000 *$ \\
\hline Status & Unmarried & $15(\mid 8.5)$ & $66(81.5)$ & & \\
\hline \multirow[t]{3}{*}{ Parity } & 0 & $14(16.2)$ & $72(83.7)$ & & \\
\hline & 2-Jan & $74(49)$ & $77(83.7)$ & 35.076 & $0.000 *$ \\
\hline & $\geq 3$ & $38(60.3)$ & $25(39.7)$ & & \\
\hline \multirow[t]{3}{*}{ Stress } & Daily 2-3 & $13(52)$ & $12(48)$ & 8.001 & $0.018 *$ \\
\hline & $\begin{array}{l}\text { times a } \\
\text { week }\end{array}$ & $91(45.9)$ & $107(54.0)$ & & \\
\hline & Never & $22(28.5)$ & $55(7 \mid .4)$ & & \\
\hline Sleep & $<7$ & $58(51.3)$ & $55(48.7)$ & 6.939 & $0.03 I^{*}$ \\
\hline \multirow[t]{2}{*}{ Time } & 9-Jul & $37(34.3)$ & $71(65.7)$ & & \\
\hline & $>9$ & $3 I(39.2)$ & $48(60.8)$ & & \\
\hline
\end{tabular}




\begin{tabular}{|c|c|c|c|c|c|}
\hline Factors & Category & $\begin{array}{l}\text { Overweight and Obesity } \\
\text { Frequency (\%) }\end{array}$ & $\begin{array}{l}\text { Non overweight and } \\
\text { obese Frequency (\%) }\end{array}$ & $\begin{array}{l}\text { Chi- } \\
\text { square }\end{array}$ & P-value \\
\hline Physical & Low & $56(87.5)$ & $8(12.5)$ & & \\
\hline \multirow[t]{2}{*}{ Activity } & Moderate & $59(37.1)$ & $100(62.9)$ & 8.232 & $0.000 *$ \\
\hline & Heavy & II(I4.2) & $66(85.7)$ & & \\
\hline
\end{tabular}

Table 7 Dietary factors associated with BMI of reproductive aged female $(n=300)$

\begin{tabular}{|c|c|c|c|c|c|c|c|}
\hline Factors & Category & $\begin{array}{l}\text { Overweightand Obesity } \\
\text { Frequency (\%) }\end{array}$ & $\begin{array}{l}\text { Non overweight and } \\
\text { obese Frequency (\%) }\end{array}$ & $\begin{array}{l}\text { Chi- } \\
\text { square }\end{array}$ & P-value & & \\
\hline \multirow[t]{8}{*}{ Calorie } & Adequate & $50(82.0)$ & II(I8.0) & 36.11 & $0.000 *$ & & \\
\hline & & Inadequate & $76(31.8)$ & $163(68.2)$ & & & \\
\hline & Carbohydrate & Low & 77 (32.8) & 161 (67.6) & & & \\
\hline & & Adequate & $38(76.0)$ & $12(24.0)$ & & 13.449 & $0.000 *$ \\
\hline & & High & II (9I.7) & $\mathrm{I}(8.3)$ & & & \\
\hline & Fruits & Regular & $35(34.3)$ & $67(65.7)$ & & 6.855 & $0.032 *$ \\
\hline & & Frequent & $9(31)$ & $20(69.0)$ & & & \\
\hline & & Rare & 82 (48.5) & $87(5 \mid .5)$ & & & \\
\hline
\end{tabular}

Table 8 Factors associated with WHR of reproductive aged female $(n=300)$

\begin{tabular}{|c|c|c|c|c|c|}
\hline Factors & Category & $\begin{array}{l}\text { Overweight and } \\
\text { Obesity Frequency (\%) }\end{array}$ & $\begin{array}{l}\text { Non overweight and obesity } \\
\text { Frequency (\%) }\end{array}$ & Chi-square & P-value \\
\hline \multirow[t]{4}{*}{ Age } & $15-19$ & $8(23.5)$ & $26(76.5)$ & 8.032 & $0.000^{*}$ \\
\hline & $20-29$ & 39 & $35(47.3)$ & & \\
\hline & $30-39$ & 71 & $22(23.7)$ & & \\
\hline & $40-49$ & 86 & $13(14.0)$ & & \\
\hline Marital & Married & I73(79.0) & $46(21.0)$ & 45.066 & $0.000 *$ \\
\hline Status & Unmarried & 31 & $50(61.7)$ & & \\
\hline \multirow[t]{3}{*}{ Parity } & 0 & 30 & $56(65.2)$ & 64.21 & $0.000 *$ \\
\hline & 3-Jan & II $7(77.5)$ & $34(22.5)$ & & \\
\hline & $\geq 3$ & 57 & $6(9.56)$ & & \\
\hline Physical & Low & 54 & $10(15.6)$ & 13.152 & $0.00 I^{*}$ \\
\hline \multirow[t]{2}{*}{ activity } & Moderate & $107(67.3)$ & $52(32.7)$ & & \\
\hline & Heavy & 43 & $34(44.2)$ & & \\
\hline Cloths & Tight & 34 & $26(43.4)$ & 4.427 & $0.035^{*}$ \\
\hline wear & Loose & $170(70.8)$ & $70(29.2)$ & & \\
\hline
\end{tabular}

Table 9 Dietary Factors associated with WHR of reproductive aged female $(n=300)$

\begin{tabular}{|c|c|c|c|c|c|}
\hline Factors & Category & $\begin{array}{l}\text { Overweight and Obesity } \\
\text { Frequency (\%) }\end{array}$ & $\begin{array}{l}\text { Non overweight and } \\
\text { obesity Frequency (\%) }\end{array}$ & $\begin{array}{l}\text { Chi- } \\
\text { square }\end{array}$ & P-value \\
\hline \multirow[t]{2}{*}{ Calorie } & Adequate & $55(90.2)$ & $6(9.8)$ & 17.286 & $0.000^{*}$ \\
\hline & Inadequate & 149 & $90(37.7)$ & & \\
\hline \multirow[t]{3}{*}{ Carbohydrate } & Low & 152 & $86(36.1)$ & 9.462 & $0.009 *$ \\
\hline & Adequate & $4 I(82.0)$ & $9(18.0)$ & & \\
\hline & High & II(9I.7) & $\mathrm{I}(8.3)$ & & \\
\hline
\end{tabular}


Table 10 Common factors associated with BMI,WC and WHR

\begin{tabular}{lll}
\hline $\begin{array}{l}\text { Indicators of Overweight } \\
\text { and obesity }\end{array}$ & Factors & $\begin{array}{c}\text { Common associated } \\
\text { factors }\end{array}$ \\
\hline BMI & $\begin{array}{l}\text { Age, marital status, parity, sleeping time, } \\
\text { Stress, calorie intake, carbohydrate intake, }\end{array}$ & \\
& Physical activity and fruit consumption & \\
WC & Age, marital status, parity, calorie intake, & Age, marital status, \\
& fat intake, Physical activity and fruit & parity, calorie intake and \\
consumption & physical activity \\
& Age, marital status, parity, cloth wear, & \\
& calorie intake, carbohydrate intake and & \\
\hline
\end{tabular}

\section{Discussion}

According to WHO BMI classification, $32.3 \%$ were found to be overweight while $9.7 \%$ were obese. Likewise the prevalence of overweight and obesity.i.e. $32.3 \%$ and $9.7 \%$ respectively which is nearly double than the national data on female where the prevalence of overweight and obesity are $17 \%$ and $5 \%$ respectively. ${ }^{16}$ The combined prevalence of overweight and obesity in this study i.e. $42.0 \%$ which is slightly greater than proportion of overweight/obese women (35\%) in Province 3. Likewise comparing this figure with a survey done in female in Srilanka where $22.8 \%$ were overweight and only $6.6 \%$ were obese.

The prevalence of abdominal obesity was found to be $68.0 \%$ (204). The mean waist to hip ratio was found to be 0.8972 which is lower than NCD risk factors survey 2013 result i.e.0.9. This study when compared to the study done in adult Malaysian abdominal obesity is found to be $75.0 \%$ which is slightly higher than result of this study i.e. $68.0 \%$. As most of the females were married in this study, postpartum weight gain could be the reason behind high prevalence of abdominal obesity as compared to male.

The mean waist circumference was found to be $86.41 \mathrm{~cm}$ which is more than the mean WC of NCD steps survey 2013(76.7 cm) conducted in Nepal. This result is similar to the survey conducted in urban India which concluded that age, marital status and parity significantly affect the BMI of female of reproductive age. It was found that increase in age, marital status and parity caused increase in BMI in female. This study revealed that majority of females i.e. $87.5 \%$ who were engaged in low physical activity were found to be more overweight and obese. A study done in Sri Lanka in adolescent obesity also concluded that those with low physical activity had four times higher risk of being obese. Similarly study done in nurses showed that daily PA was associated with less weight gain. Low levels of exercise and sedentary behavior have predicted storage of fat in abdominal tissue and leading future weight gain among adults.

This study showed that overweight and obesity was found more in females consuming more calories .i.e. $74.2 \%$ than females consuming inadequate calories .i.e. $32.9 \%$. Similarly, a study done in South India also supported our results which showed higher prevalence of overweight and obesity in females consuming adequate calories High calorie intake than the requirement, results in storage of fat in the body leading to overweight and obesity. This study concluded that females consuming high carbohydrate were found to be more overweight and obese i.e. $91.7 \%$ than females consuming low and adequate carbohydrate. According to Dam and Seidell carbohydrates are the macronutrients that provide energy and can thus contribute to excess energy intake and subsequent weight gain. This study concluded that females consuming fruits rarely were found to be more overweight and obese i.e. $48.5 \%$ than females consuming fruits more frequently. Likewise, study conducted in urban school adolescents in Nepal also concluded that students who consumed fruit four times or less a week were three times more likely to be overweight than students who consumed fruit more than four times per week.

For abdominal obesity by WC, our study showed that abdominal obesity was more prevalent in females consuming adequate calories i.e. $90.2 \%$ than females consuming inadequate calories. This study resulted that overweight and obesity was more prevalent i.e. $79.1 \%$ in females consuming high fat diet which is supported by the study done by Costa which concluded that high fat intake significantly increases total and visceral fat mass leading to overweight and obesity. This study showed that abdominally obesity was more prevalent i.e. $79.2 \%$ in females consuming fruits rarely. Likewise, a cohort study performed concluded that increased intake of fruits was inversely associated with changes decrease in waist circumference. As fruits are rich in dietary fiber, they reduce the energy density of diet and promote satiety. This study showed that that abdominal obesity was more prevalent i.e. 70.3 $\%$ in females consuming inadequate protein than females consuming adequate protein but association was not found between protein intake and abdominal obesity. Likewise, a study conducted in obese females resulted that high protein diet actually helps in losing weight.

Similarly for abdominal obesity by WHR, Overweight and obesity was more prevalent .i.e. $86 \%$ in older age group females. In the study done in Iraqi women positive association was found between abdominal obesity and age. This study shows that females performing low physical activity were more abdominally obese comparedto females with heavy physical activity i.e. $84.3 \%$. This finding was supported by the study performed by Siddiquee which also showed positive association between physical activity and abdominal obesity can be explained as physical activity helps in maintaining healthy weight by balancing energy intake and expenditure. This study showed that that abdominal obesity was more prevalent .i.e. $70.3 \%$ in females consuming inadequate protein than females consuming adequate protein but association was not found between protein intake and abdominal obesity. In a study done by Merchant high protein intake was associated with low abdominal obesity. The satiating capacity of protein rich food and their role in fat utilization of body, they are actually beneficial in losing weight. 


\section{Conclusion}

Obesity has become common place in many low- and middleincome countries, and the prevalence of obesity has increased in such countries, particularly in South Asia. Changing dietary habits can shift a society's disease pattern from infectious, communicable diseases' dominance towards a status of double-disease burden with increasing prevalence of obesity and non- communicable diseases (NCDs). ${ }^{24}$ In Nepal trends of overweight and obesity is found to be increasing in both male and female with $7.1 \%$ overweight and $2.4 \%$ obesity to $22.1 \%$ overweight and $4.8 \%$ obesity between 2007 to 2013 . Similarly mean waist to hip ratio was found to be 0.55 in 2007 study while 2013 STEPS survey shows this figure to 0.9 . The current prevalence of overweight and obesity is more among females as compared to males in Nepal (MOHP, 2008, 2013b). The combined prevalence of overweight and obesity in female has increased from $1.6 \%$ to $22.2 \%$ in 2016 and in men overweight and obesity is found to be $17 \%$.

Our study resulted that Nearly half of females (42\%) were overweight and obesity in reproductive aged females in Bharatpur metropolitan city. Therefore, the result of this conclude rising prevalence of overweight/obesity as a serious health challenge, which must be taken seriously and preventive measure must be taken to prevent overweight and obesity. Thus, obesity must be considered a chronic disease which must be treated like any other medical condition, and if not treated it leads, insidiously, to the development of numerous diseases.

\section{Acknowledgments}

a. Damber Bahadur Khadka, HOD, Nutrition and Dietetics, Central Campus of Technology, Dharan Nepal

b. AnuskhaLamichanne, my senior who helped me during the data collection period.

\section{Conflicts of interest}

There are no conflicts of interest

\section{Funding}

None.

\section{References}

1. WHO. Overweight and obesity. Geneva; 2017.

2. IDF. The IDF consensus worldwide definition of the metabolic syndrome. Belgium; 2006.

3. WHO. Waist Circumference and Waist-Hip Ratio. Geneva; 2008.

4. WHO. Definition, diagnosis and classification of diabetes mellitus and its complication. Geneva; 2011.

5. Regina W Mbochi, Elizabeth Kuria, Judith Kimiywe, et al. Predictors of overweight and obesity in adult women in Nairobi province, Kenya. BMC Public Health. 2012;12:823.

6. Paul Mawaw, Thierry Yav, Olivier Lukanka, et al. A cross-sectional study on obesity and related risk factors among women of the central market of Lusonga in Lubumbashi, Democratic Republic of Congo. Pan Afr Med J. 2017;28:157
7. Pi-Sunyer FX. Comorbodities of overweight and obesity: Current evidence and research issues. Med Sci Sports Exerc. 1999;31(11):602-608.

8. WHO. Reproductive Health Indicators. 2006.

9. Lovney Kanguru, Affette McCaw-Binns, Jacqueline Bell, et al. The burden of obesity in women of reproductive age and in pregnancy in a middle-income setting: A population based study from Jamaica. PLoS One. 2017;12(12): 0188677.

10. UNDP. Human development report. Washington DC; 2016.

11. CBS. Population monograph of Nepal. 2014.

12. WB. Urban population growth (annual \%) in Nepal. 2014.

13. MOHP. NCD risk factors survey (2007-2008) Nepal; 2008. p. 44-49.

14. MOHP. Non Communicable Diseases Risk Factors: STEPS Survey Nepal 2013, Nepal Health Research Council (NHRC): Nepal; 2013.

15. MOH. Nepal Family Health Survey. 1996.

16. MoH N ERA. Nepal Demographic and Health Survey 2016. Nepal; 2016.

17. Anon. Bharatpur metropolitan city. 2018.

18. Ghaffar A, KS Reddy, M Singhi. Burden of non-communicable diseases in South Asia. BMJ. 2004;328:807-810.

19. Balkau B. International day for the evaluation of abdominal obesity(idea): A study of waist circumference, cardiovascular disease, and diabetes mellitus in 168,000 primary care patients in 63 countries. Circulation. 2007;116:1942-1951.

20. Balarajan Y, E Villamor. Nationally representative surveys show recent increases in theprevalence of overweight and obesity among women of reproductive age in Bangladesh, Nepal, and India. The Journal of Nutrition. 2009;139:2139-2144.

21. WHO. Global Strategy on Diet, Physical Activity and Health. 2017.

22. Bhurosy $\mathrm{T}$, Jeewon R. Overweight and obesity epidemic in developing countries: A problem with diet, physical activity, or socioeconomic status? Scientific World Journal. 2014;4.

23. Vaidya A, S Shakya, A Krettek. Obesity prevalence in Nepal: Public health challenges in a low-income nation during an alarming worldwide trend. Int J Environ Res Public Health. 2010;7:2726-2744.

24. WHO. Non-comuunicable Diseases Progess Monitor. Geneva; 2017.

25. Neupane D, Kallestrup P. Non-communicable Diseases in Nepal: Challenges and Opportunities. 2013;11(24):225-228.

26. CBS. Population monograph of Nepal. 2003. p. 381-389.

27. Gonzalez E. Obesity: Etiologic and pathophysiological analysis. Endocrinology nutrition. 2013;60(1):17-24.

28. Sartorious B. Determinants of obesity and associated population attributability, South Africa: Empirical evidence from a national panel survey, 2008-2012. Plos One. 2015.

29. Srilakshmi B. Dietetics. 7th ed. New Delhi: New age international; 2014. 